\title{
Notas Preliminares para um Estudo de Aluizio Azevedo
}

GE Aluizio Azevedo ${ }^{1}$ depois da publiçao de $O$ Mulato em 1881, tivesse seguido o conselho the dado por um crítico maranhense, nunca teria chegado a ser "o pai do realismo brasileiro". Com effeito, o senhor Euclides Faria escrevendo no número de julho de 1881 no jornal Civilização, dirigiul-lhe as seguintes palavras:

Eis ahi um romance realista, o primeiro pepino que brota no Brazil. E' muita audacia ou muita ignorancia ou ambas as coisas ao mesmo tempo! E' contar de mais com a ignorancia dos leitores, com a benvolencia da critica nacional, e julgar os outros por si. Permitta o jovem zote, autor do Mulato que me admire ainda uma vez. A sua comprehensão sobre o realismo é de eternas luminarias! Methor seria fechar os livros, ir plantar batatas!

Convem indicar que o citado redator era dos mais destacados no Brasil, e que a sua opinião era muito acatada. Porêm, Azevedo nem se dedicou â vida do campo, nem se deixou intimidar. Ao contrario, não tardou em se ver aclamado, o seu Mulato causando ruidosa repercussóes em todo o pais. Como se sabe, Aluizio, a pesar da inimizade da sua própria província, estava destinado a ser um dos primeiros brasileiros que prosperassem por meio da pena.

Geralmente se admite que Azevedo foi "o Zola brasileiro" 2 mas neste ponto não desejamos insistir, visto que aqui não tencionamos fazer um estudo comparativo nem nos metermos no intricadissimo labirinto de fontes literárias. Todavia, tal estudo tomaria em consideração, além do naturalista francês, a pontente e innegável influência do português, Eça de Queiroz (mas a fina estética de Eça 
nunca podia ser plenamente compreendida pelo espírito prático do brasileiro). Também, um estudo completo indagaria as possiveis influências de escritores nacionais sôbre Azevedo. Embora, seja dita a verdade, esta tarefa seria brevissima - porque todo estudante da literatura do Brasil sabe em que condições se achava o realismo ao aparecer Azevedo, e quão insignificante devia ser a herança recebida por ele dos seus precursores "realistas". As aventuras sentimentais dos indios falsos dum José Alencar, a arte fotográfica dum Manoel de Almeida, assim como as paisagens poéticas dum Bernardo Guimarães, pouco podiam influir no temperamento combativo e reformador do jovem maranhense.

Em verdade, uma biografia de Aluizio poderia bem começar com a descrição da sua entrada no mundo de letras, em primeiro lugar, porque faltam muitos pormenores da sua juventude, em segundo lugar, porque isto nos proporciona a melhor chave à inteligência do autor. Em $1880 \mathrm{fez}$ sua aprendizagem jornalística no diario $A$ Pacotilha, dirigido pelo seu cunhado, Vitor Lobato. No mesmo ano Azevedo, em colaboração com Eduardo Ribeiro e Pedro Freire, fundou o Pensador, de tendências radicais e anticlericais. $\mathrm{O}$ atrevido jornalsinho provocou escâdalos que agitaram a inteira provincia de Maranhão, e a policia interveiu. Depois dum ruidoso processo o malfadado Pensador foi suspenso. Mas o intrépido. escritor, desafiando outra vez as autoridades, não tardou em lançar o Mulato, ${ }^{3}$ muito mais atrevido na sua crítica social do que o jornal condenado, e que resultou um verdadeiro "succès de scandale". Eis, então, o caso dum jornalista frustrado, que verte todo o seu azedume, toda a sua indignação, numa outra forma literária - o romance.

Era, pois, o seu infreiável prurido de dizer as verdades que the grangearam a inimizade de toda a sua provincia natal e o seu renome como naturalista brasileiro. Estava resolvido a se fazer ouvir, custasse o que custasse - a expôr os males do Brasil, quer fôse em forma jornalística, ou em forma romancista. Não obstante, haverá quem diga que Azevedo não sempre era fiel ao realismo, cometendo o crime literário de escrever uma série de romances-folhetins. ( $A$ Mortalha de Alzira, Misterios da Tijuca, etc.) Estas obras, à maneira de Dumas são labirintos de intriga e de aventura romântica, de pouco valor artístico. A pesar disso, podemos até certo ponto defender o autor, afirmando que são uma simples concessao à questao do "pao quotidiano", e admissíveis num homen que tanto fez para o realismo. 
Além do qual, cumpre frisar que mesmo nestas obras irreais o romancista nunca deixou escapar uma só oportunidade para atacar a sociedade contemporânea.

Deixemos aparte os folhetins para fazer algumas observações sôbre os romances representativos do maranhense ( $O$ Mulato, $O$ Coruja, O Cortiço, Casa de Pensão). O leitor ficará desapontado se procurar nêles essas intermináveis séries de escabrosidades, tão "objetivamente" presentadas pelos franceses. $\mathrm{Ha}$ de se convencer finalmente que o decantado naturalismo do "Zola brasileiro" difere em dois pontos importantes dos modêlos europeos: 1) não insiste, nem se interessa pela teoria do "determinismo", nem a explora para explicar e justificar a conduta dos individuos ; 2) evita uma apresentação excessiva das fealdades humanas, que sabe descrever quando é necessario, mas que não o obcecam. Tambên faltam em Azevedo as descrições minuciosas e aborrecidas, tão caras ao coração dos escritores dedicados ao "método experimental". Em outras palavras desenvolve um naturalismo abrasileirado e naturalizado. Tal vez seja mais exato calificá-lo como o faz o erudito historiador da literatura brasileira Afranio Peixoto, quem o chama simplesmente "Romancista de forte compleição". ${ }^{4}$

Tudo o qual equivale a dizermos que Aluizio Azevedo tem tendências naturalistas - que é talvez naturalista. Mas, na verdade, não lhe interessam teorias literárias, nem efusões artísticas, nem questôes de estilo e de linguagem. Exclue como estranho tudo o que só sirva para fotografar, sem contribuir a analisar ou interpretar o homem. Em lugar do principio "a arte pela arte" crê na "arte pelo homem".

E' porisso que um estudo completo sôbre Azevedo tem forçosamente que gravitar em volta de seus personagens. Porém aqui não ambicionamos mais do que citar umas notas breves com respeito a êles. Como orientaçao geral para a sua análise, indicamos que Aluizio Azevedo parece incapaz de apresentar convincentemente um individuo bom, normal, lowvável, mas pinta duma forma admirável qualquer individuo mau, egoista, anormal, excêntrico, desequilibrado: Nisto consiste o seu naturalismo, e não no desejo de exhibir ante os olhos do leitor as pequenas e grandes misérias da existência humana. Contudo, por ruins que sejam os carateres ${ }^{5}$ de Aluizio, nunca tem aquele aspecto do "mal encarnado" tão típico do século xıx : conduzem-se com 
finura e até com certo encànto - o que lhes proporciona muita modernidade.

Vejamos, por exemplo, o famoso padre do Mulato:

O cônego entrou, de vagar, com o seu sorriso discreto e amável. Era um velho bonito; teria quando menos sessenta anos, porém estava ainda forte e bem conservado; o olhar vivo, o corpo têso, mas ungido de brandura santarrona. Calçava-se com esmero, de polimento; mandava buscar da Europa, para seu uso, meias e colarinhos especiais, e, quando, ria, mostrava dentes limpios, todos chumbados a ouro. Tinha os movimentos distintos: mãos brancas e cabelos alvos que fazia gôsto... Formárarse em Coimbra, donde contava matavilhas; um bocadinho rico, e não relazava o seu passeio a Lisboa, de vez em quando, "para descartegar anos da costa..." explicava êle, a rir. ${ }^{6}$

O padre é ambicioso, e satânicamente hábil para enganar. Abusa do confessionário, e o que é ainda peor, persegue duma forma pouco cristão pobre mulato Raymundo. Mas tudo o faz com uma elegância e com uma profunda compreensão da psicologia humana. Exemplo disto é a scena onde o padre Diogo tira uma confissão a Anna Rosa, amante do mulato:

O cônego Diogo calculara bem. A encenação da missa, os amolecedores perfumes da igreja, o estômago em jejum, o venerando mistério dos latins, o ceremonial religioso, o esplendor dos altares, as luzes sinistramente amarelas dos círios, os sons plangentes do orgão, impressionaram a delicada sensibilidade nervosa da afilhada e quebrantariam o seu ânimo altaneiro, predispondo-a para a confisao... Então!... vamos... disse o padre com brandura. Não tenha medo!... Isto é apenas uma conversa que a senhora tem com a sua própria conciência, ou com Deus, que vem a dar na mesma... Conte-me tudo!... abra-me seu coração!... Fale, minha afilhada!... Aquí eu represento mais do que seu pais; se fôse casada, mais que seu marido! sou o juiz, compreende? represento Cristo! represento o tribunal do céu! Vamos, conte-me tudo, e eu the conseguirei a absolviçao!. . . eu pedirei ao Senhor Misericordioso o perdão dos seus pecados! $\mathbf{7}$

O cônego, para impedir o casamento de Anna Rosa com o mulato, faz como que o Dias mate Raymundo - depois chora ã sepultura dêste. Não é totalmente maut! Quanto ao Mulato (caráter bom, porisso mal apresentado) deixa de nos comover como pessoa real; reune muitas boas qualidades e fica sendo constantemente perseguido 
peola ruindade e pelos preconceitos da alta sociedade maranhense. Representa um problema social, e não um homem de carne e ôsso.

Consideremos alguns outros casos. O romance do Coruja pretende ser o estudo dum homem quintessencialmente altruista, quasi um "Don Quixote", e do setı inevitável fracasso. Apesar disso André o "coruja" não nos interessa como pessoa, nem como idéia, nem como creação. Ao contrário, Teobaldo (caráter mau) sendo a sua antítese em tudo, é quem chama e absorbe a nossa atenção. Alguns vem na figura do Teobaldo uma análise de Dom João VI; seja isso como fôr, constitue um verdadeiro triunfo literário. Teria pouco de excepcional se fosse só outro aventureiro vulgar e "arriviste", dos que abundam por exemplo em Le Nabab de Daudet; o caso é que se nos apresenta como homem elegante, refinado, de cultura e de sensibilidade estética. Tem um modo de se insinuar - e chega a desempenhar as mais altas funções nacionais. $O$ povo o idolatra, sem nunca suspeitar que o seu héroi é incurávelmente egoista: nunca fez nada para ninguém. Todavia, é um político pouco comun, do ponto de vista literário, visto que não aproveita o seu pôsto, sendo ministro, para espoliar a gente. Resulta um pouco teatral a sua môrte numa isolação espiritual e psicológica, o porque "veio-lhe o tédio, o desprêso próprio, a grande moléstia dos que sobem sem convicçao e sem causa" \$ mas exluindo isto o estudo do Teobaldo é admirável:

A singularissima posição de Teobaldo entre a chamada melhor sociedade do sea tempo vinha pura e simplesmente das graças dêle, do seu talento do sabet, como ninguém dar a cada um individuo aquilo que the era mais lisongeiro ou agradável; vinha de conseguir agradar ao gôsto de todos, desde o Imperador, até o último dos copeiros sem aliás desgostar a ninguém ... pândego para os pândegos, homem serio para os sérios, êle a todos e com todos se afinava, sem aliás perder uma linha da originalidade do seu tipo. 9

O romancista maranhense chega a delinear um tipo muito raro na literatura, embora omnipresente na vida, desde que ha havido grupos, organizadores, chefes, e "lideres": $O$ homem que encanta e seduz, atingindo o auge do poder, não por mérito, senão pela seduçao de maneiras, ligađa a uma eloqüencia ôca:

Sem fazer nada, parecia fazer tudo porque nas câmaras a sua palavra era sempre a mais destacável entre os colegas. Além de que, afetava uma grande atividade espetaculosa; não havia inauguração 
de estrada de ferro, ou de qualquer fábrica industrial ou cousa dêeste gênero, que êle não acompanhasse de corpo presente, fingido ligar a isso grande atenção e derramando-se em longos discursos talhados ao sabor do auditório que encontrava. 10

Apressemo-nos a dizer aquí que não todos os tipos de Azevedo são tão elegantes nem tão bem definidos como Teobaldo ou como o padre Diogo. Como a maioría dos realistas do seu dia pinta dois meios: a alta sociedade e o bairro baixo. O melhor exemplo disto é, na nossa opiniao, $O$ Cortiço, um dos poucos romances brasileiros até agora honrados com uma tradução inglesa. ${ }^{11}$ Quasi juxtapostos neste livro encontramos o "haut monde", com cenário na casa de Miranda, e a plebe nos rudes "cortiços". Aquí pululam prostitutas, lavadeiras, pedreiros, parasitas de toda espécie, tipos rudimentares. Quiseramos sugerir que $O$ Cortiço é uma epopéia de bairro baixo fluminense, cantada com uma evidente simpatía de parte do autor para com os pobres, e com um aparente desdém para com os ricos e os aristocratas. Cabe também sublinhar que Azevedo sobresae em descrever os grupos, especialmente os grupos em açao, ponto que o liga com Zola (Le Ventre de Paris, La Débâcle, etc.) Deleita-se em nos descrever uma festa, um combate travado entre dois cortiços rivaes, ou simplesmente umas lavadeiras ocupadas com a sua tarefa:

A labutação continuava. As lavadeiras tinham já ido almoçãr e tinham voltado de novo para o trabalho. Agora estavam todas de chapéu de palha, apezar das toldas que se armaram. Um calor de caustico mordialhes os toutiços em brasa e cintilantes de suor. Um estado febril apoderava-se delas naquele rescaldo: aquela digestão feita ao sol fermentava-1hes o sangue. A Machona altercava com uma preta que fôra reclamar um par de meias e destrocar uma camisa; a Augusta, muito mole sobre a sua taboa de lavar, parecia derreterse como sebo; a Leocadia largava de vez em quando a roupa e o sabão para coçar as comichões do quadril e das virithas, assanhadas pelo mormaço; a Bruxa monologava, resmungando numa insistencia de idiota, ao lado da Marciana que, com o seu tipo de mulata velha, um cachimbo ao canto da boca, cantava toadas monotonas do sertão:

\footnotetext{
Maticas tá matimbando, Maticas tá matimbando, Na passage do riacho, Maticas tá marimbando.
} 
... Da casina numero 8 vinha um falsete agudo, mas afinado. Era a das Dores que principiava o seu serviço; não sabia engomar sem cantar. No numero 7 Nênêm cantarolava em tom muito mais baixo; e de um dos quartos do fundo da estalagem saía de espaço a espaço uma nota áspera de trombone. $O$ vendeiro, ao passar por detrás de Florinda, que no momento apanhava roupa do chão, ferrou-lhe uma palmada na parte do corpo então mais em evidencia. 12

Compreende-se porque o senhor Golberg, profundo conhecedor das letras brasileiras, observa: "Aluixio Azevedo's types... are the opposite to Machado de Assis's; they are coarse, violent, terre à terre." 13

Deveriamos falar muito mais da rica galeria de tipos que abundam nos romances do escritor maranhense, porque com êle - são tudo. Embôra, deixemos êste assunto para fazer dois comentários adicionais. O primeiro é para censurar em Azevedo a sua tendência excessiva a pregar. Começou como reformador social e reformador social sigue sendo. Na maneira dum Messias elegido para condenar os males da Civilisaçao, constitue-se em "coro grego" para falar diretamente ao leitor. Mesmo na sua novela Uma Lágrima de Mulher, totalmente romântica e falta de realismo, interpõe-se para dizer:

O ouro derretera-se, dêle levantaram-se as duas espirais de fumo -Civilisação e Hipocresia. Estas duas fôrças produzem um fluido capaz de transformat um anjo em mulher e uma mulher em demônio. 14

Esta tendência mostra-se mais marcada, quando se trata da alta sociedade ou dum ambiente aristocrático, que Aluizio detesta, como já vimos.

O segundo é último ponto que desejamos salientar concerne o humorismo do autor - cousa bastante rara num escritor de colorido naturalista. Parece crer com Pascal, quem cita no frontispício de $A$ Mortalha de Alzira: "L'homme n'est donc qu'un sujet plein d'erreurs; rien ne lui montre la vérité; tout l'abuse", mas apesar disso, e da sua simpatia pelo homem, não se compunge em caçoar do gênero humano. A sua veia humorista pode manifestarse como pura farsa (Philomena Borges) ou nos momentos mais graves, como tragicomedia. Descrevendo o enterro de Teobaldo, o homem de "bom gôsto" Aluizio diz: 
Dir-se-ia que de dentro do seu rico caixão, coberto de crepe e engenhosamente entretecido de fúnebres coroas, Teobaldo dirigia o solene préstito que o acompanhava à sepultura. Esperava-se ver a cada momento surgir entre as abas do caixão a cabeça do grande homem de gôsto exclamando para algum soldado que saira da fileira:

-..Mais para a direita! P'ra direita! Em linha! 15

Azevedo sabe rir, o que interpretamos como sinal da sua mentalidade sadia, a pesar das suas qualidades pessimistas-naturalistas.

Em conclusao a atividade literária de Azevedo abrangeu um periodo de sómente quinze anos (1880-1894). No ano 1894 ingressou no serviço consular, abandonando para sempre o mundo das letras. Nem elle nem nenhum outro naturalista brasileiro empreendeu uma série da amplitude da Comédie Humaine de Balzac ou, da série Rongon Macquart de Zola. Embora, o gênio combativo e realista do "neo-naturalista" Aluizio Azevedo deixou-nos obras valiosas como documentos do Segundo Imperio, além do set interesse como romances.

\author{
JACOB Ornstein, \\ Washington University, \\ St. Louis, Mo.
}

\title{
$N O T A S$
}

1. O fim das nosas observações é de sugerir as linhas gerais que seguirá um estudo de conjunto projetado sobre o autor, quem merece mais atenção do que o que tem recebido no passado. Devido à brevidade do presente trabalho, não fazemos nenhum reclame de finalidade. Aluizio Azevedo (1857-1913) escreveu os seguintes romances: Uma Lágrima de Muthet, O Mulato, A Condessa Vesper, Girândola de amores, Casa de Pensão, Philomena Borges, O Homem, O Cortja, O Cortiço, O Esqueleto, A Mortalha de Alzita, Livro de Uma Sogra, Demônios, O Touto Negro. Estas obras completas estão magníficamente editadas pelo eminente Dr. M. Nogueira da Silva, da Academia Carioca de Letras. (F. Briguiet, Rio, 1937-1941). Na introduçãa a Uma Lágtima de Muther o editor inclue uma completa biografía do romancista.

2 A "escola" de naturalistas brasileiros está constituida, além de nosso. autor, por Machado de Assis, Julio Ribeiro, e Raúl Pompeia, os quais, naturalmente, convem tratar por alto no estudo de conjunto.

3 O Mulato não foi o sue primeiro tomance, senão Uma Lágrima de Muther, aparecendo em 1880. Mas esta obra é quasi totalmente atípica, seguindo a veia Lamartiniana e sendo do romantismo mais desenfreiado. 
4 Afranio Peixoto, Panotama da literatura brasileita, Rio, 1940, pág, 475 .

5 Importante questão para indagarmos no estudo completo de Aluizio: até que ponto baseou a sua caraterização sôbre pessoas que viviam na sua época, e que conhecia? Há indicaçãos que alguns romances do autor eram, pelo menos em parte, "romans à clef": vejam Nogueira da Silva, na introdução ao Cotuja, pág. 7.

6 O Mulato, edição citada, pág. 37.

7 Ibid., págs. 324-326.

8 O Coruja, pág. 401.

9 Ibid., pág. 332.

10 Ibid., pág. 396.

11 Tradução feita com mestria pelo senhor Harry W. Brown em 1926 (Robert M. McBride and Co., New York). Na sou introdução o senhor Brown faz o seguinte comentário interessante: "A number of incidents and details have been omitted from the English version owing to the squeamish sensibilities of our reading public, whose philosophy is that of the ostrich."

12 O Cortiço, edição citada, págs. 57-58.

13 Isaac Goldberg, Brazilian Literature, Knopf, New. York, 1922, pág. 122.

14 Uma Lágtima de Mulhet, pág. 56.

15 O Coruja, pág. 421. 
